Supporting Information

\title{
Pd- and Au-Induced Circular and Fibrous Polymer Gelation via Thiocarbonyl Groups and High Pd Catalyst Activity
}

Daisuke Nagai, ${ }^{\star}{ }^{\ddagger}$ Ayaka Kubo, ${ }^{\dagger}$ Moeko Morita, ${ }^{+}$Naoyuki Shimazaki, ${ }^{\dagger}$ Yasuyuki Maki

\& Hiroyuki Takeno, ${ }^{+}$Masanobu Mori,l Hiroki Uehara, ${ }^{+}$and Takeshi Yamanobe ${ }^{\dagger}$

† Division of Molecular Science, Faculty of Science and Technology, Gunma University, 1-5-1 Tenjin-cho, Kiryu, Gunma Prefecture 376-8515, Japan

‡Present address: School of Food and Nutritional Science, University of Shizuoka, 521 Yada, Shizuoka-shi 422-8526, Japan

$\S$ Department of Chemistry, Graduate School of Science, Kyushu University, 744 Motooka, Nishi-ku, Fukuoka, Fukuoka, 819-0395, Japan

\| Department of Materials Science and Engineering, Kochi National College of Technology, 200-1 Monobe otsu, Nankoku, Kochi, 783-8508, Japan 
*Correspondence to: D. Nagai (E-mail: daisukenagai@u-shizuoka-ken.ac.jp, Tel \& Fax: +8152-264-5729)

\section{Note $\mathbf{S 1}$.}

We examined the other kinetics, and the correlation coefficients of Pd-crosslink and Aucrosslink of pseudo first-order kinetics (0.9799 and 0.9604), pseudo second-order kinetics (0.1440 and 0.9462), and diffusion kinetics (0.9507 and 0.9658). Therefore, pseudo first-order kinetics, which represents the kinetic experimental data for the rapid initial phase (Nagai, D. et al. RSC Adv. 2016, 6, 103303), was applied.

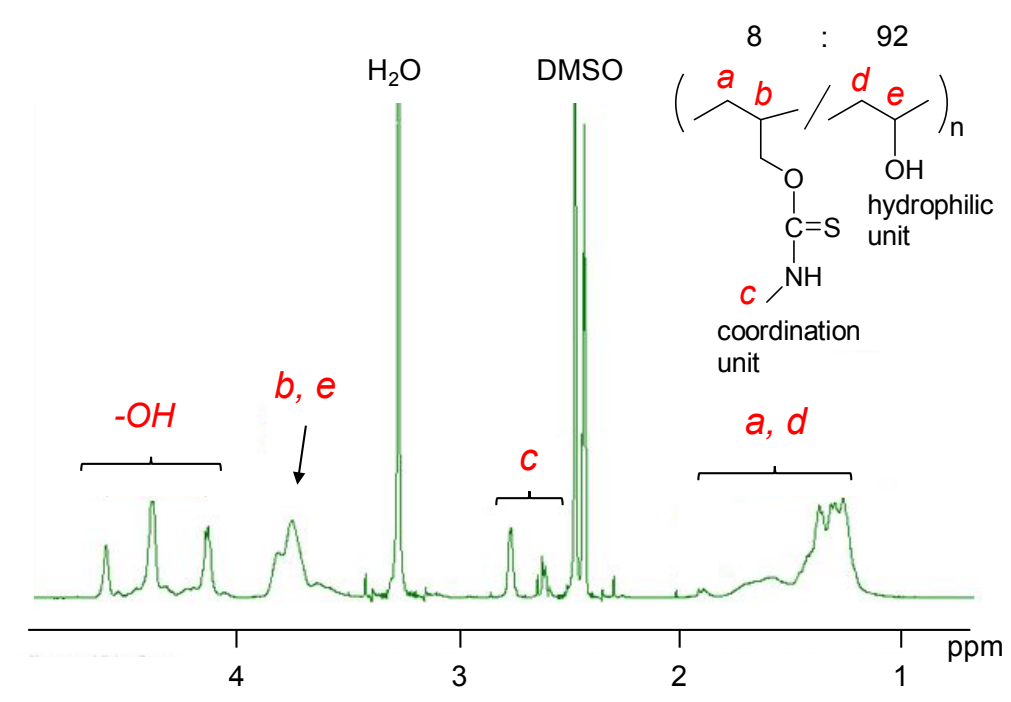

Figure S1. ${ }^{1} \mathrm{H}$ NMR spectrum (DMSO-d 6 , at rt) of HPMC.

The ${ }^{1} \mathrm{H}$ NMR spectrum showed signals assignable to the metal-coordination and hydrophilic units. Based on the integral ratio of these units, the composition ratio was 8:92 (Figure S1). 
(a)

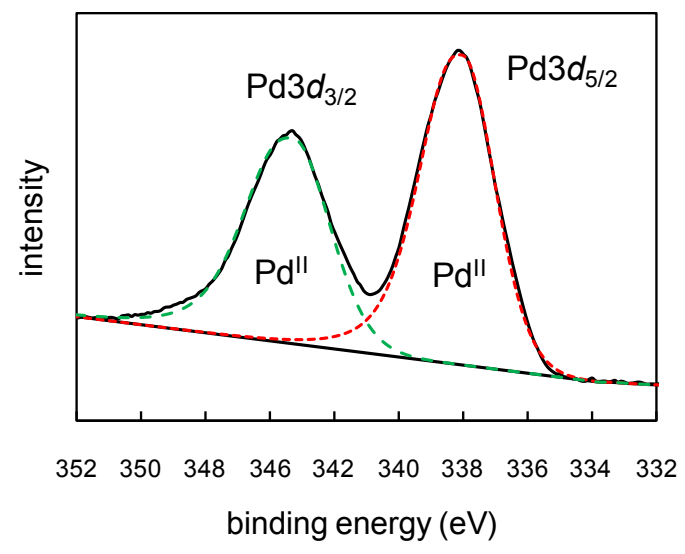

(c)

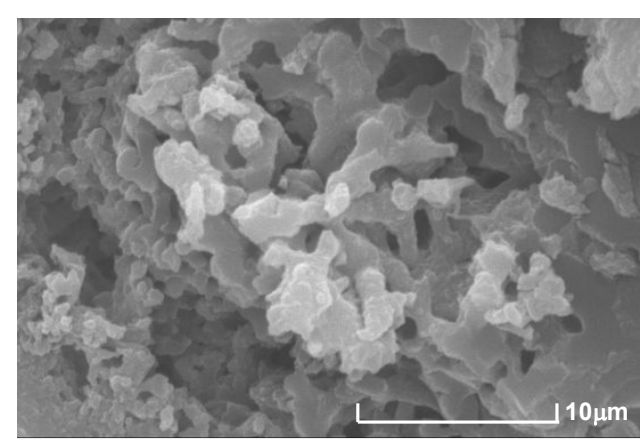

(b)

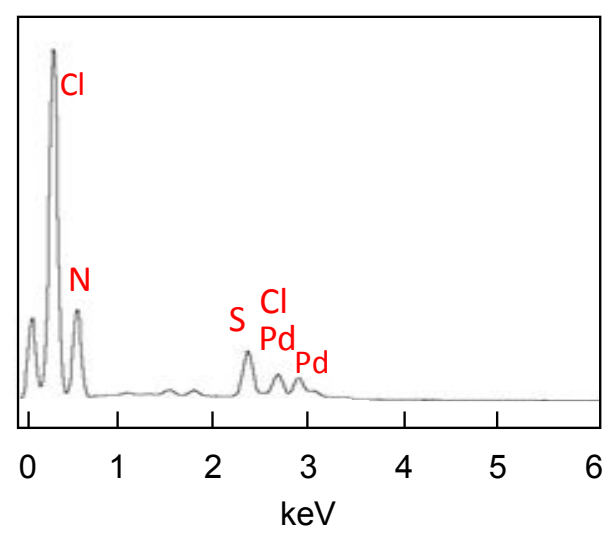

(d)

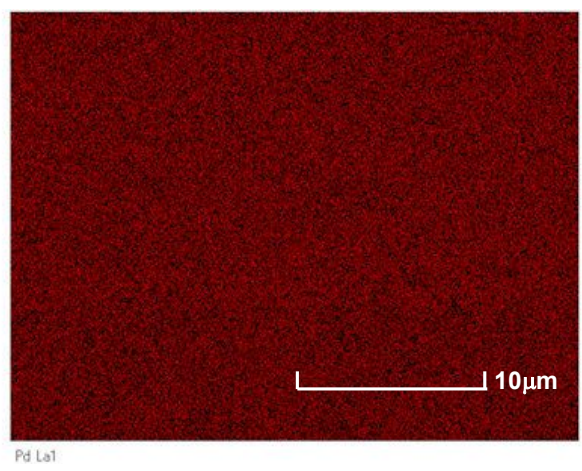

Figure S2. (a) XPS spectrum of HPMC-Pd-C. (b) EDX spectrum of HPMC-Pd-C. (c) SEM image of HPMC-Pd-C. (d) EDX/SEM mapping image of Pd. Red dots is Pd species.

The XPS spectrum of HPMC-Pd-C showed $\mathrm{Pd} 3 d_{5 / 2}$ and $\mathrm{Pd} 3 d_{3 / 2}$ peaks at $337.9 \mathrm{eV}$ and 343.2 $\mathrm{eV}$, respectively, which are typical of $\mathrm{Pd}^{\mathrm{II}}$ species (Figure S2a). The EDX/SEM results indicated the presence of Pd and $\mathrm{Cl}$ species (Figure S2b). The SEM image of HPMC-Pd-C showed the rough surface (Figure S2c). The EDX/SEM mapping image showed that $\mathrm{Pd}$ species (red dots) were uniformly dispersed in HPMC-Pd-C (Figure S2d). 
(a)

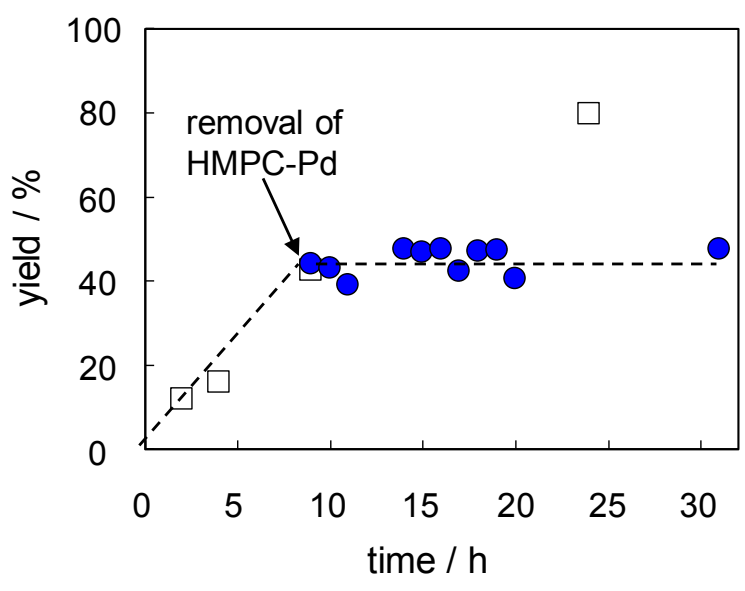

(b)

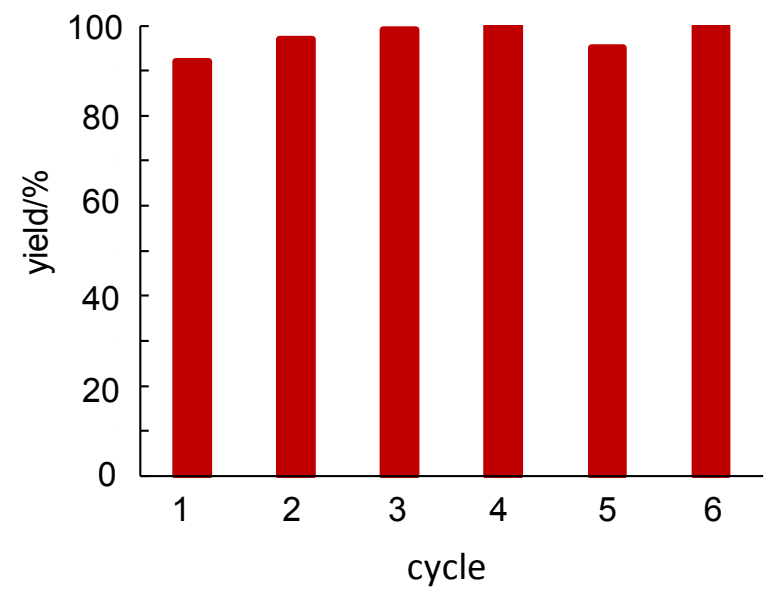

Figure S3. (a) Control experiment for Mizoroki-Heck reaction of iodobenzene and styrene. Conditions: $[\text { iodobenzene }]_{0}=1.0 \mathrm{M}$; [alkene $]_{0}=1.2 \mathrm{M}$; HPMC-Pd-C $=7.85 \mathrm{mg}\left(1.5 \times 10^{-4} \mathrm{mmol}\right.$ of $\mathrm{Pd}, 0.03 \mathrm{~mol} \%$ of $\mathrm{Pd}$ to aryl halide); NMP $=5.0 \mathrm{~mL}$; undecane $=0.4 \mathrm{~mL}$; reaction temperature $=140^{\circ} \mathrm{C}$. (b) Reusability of HPMC-Pd-C in the Heck reaction of iodobenzene and styrene in NMP. Conditions: [iodobenzene $]_{0}=1.0 \mathrm{M}$; [styrene $]_{0}=1.2 \mathrm{M} ; \mathrm{HPMC}-\mathrm{Pd}-\mathrm{C}=$ $7.85 \mathrm{mg}\left(1.5 \times 10^{-4} \mathrm{mmol}\right.$ of $\mathrm{Pd}, 0.03 \mathrm{~mol} \%$ of $\mathrm{Pd}$ to aryl halide $)$, NMP $=5.0 \mathrm{~mL}$; undecane $=$ $0.4 \mathrm{~mL}$; reaction temperature $=140^{\circ} \mathrm{C}$; reaction time $=20 \mathrm{~h}$.

In the reaction of iodobenzene and styrene, a control experiment was conducted to confirm that the insoluble catalyst promoted the reaction under heterogeneous conditions. The reaction was performed under conditions identical to those in Table 1, entry $6(1.0 \mathrm{M}$ iodobenzene, $1.2 \mathrm{M}$ styrene, $0.03 \mathrm{~mol} \%$ of $\mathrm{Pd}$ in HPMC-Pd-C to iodobenzene, $1.0 \mathrm{M}$ tributylamine, $0.5 \mathrm{M}$ undecane, $\left.140^{\circ} \mathrm{C}\right)$. After $8 \mathrm{~h}(43 \%$ product yield), the catalyst was subjected to membrane filtration (pore size $=0.45 \mu \mathrm{m}$ ), and the filtrate stirred for an additional $24 \mathrm{~h}$. Gas chromatography showed that the reaction did not proceed further, whereas the yield reached $80 \%$ in the presence of HPMC-Pd-C for $24 \mathrm{~h}$ (Figure S3a). To investigate reaction economy, the reusability of HPMC-Pd-C was examined for Mizoroki-Heck reaction of iodobenzene and styrene in NMP at $140^{\circ} \mathrm{C}$ for $24 \mathrm{~h}$. After the first reaction, which produced a $92 \%$ yield of the corresponding product, HPMC-Pd-C was recovered by filtration. The catalyst was subjected to five more cycles under similar conditions, and gave the product without loss of catalytic activity, indicating the high recyclability of HPMC-Pd-C (Figure S3b). 
(a)

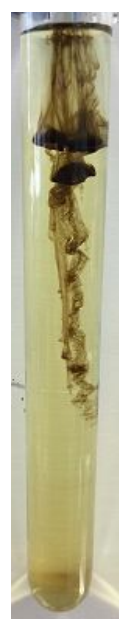

(b)

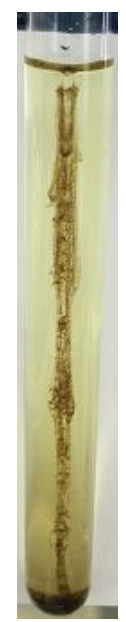

(c)

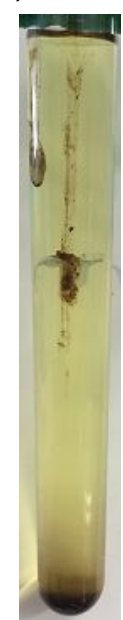

Figure S4. Photographs of gels produced upon addition of dispersed aqueous solutions of (a) $13 \mathrm{wt} \%$; (b) $11 \mathrm{wt} \%$; and (c) $9 \mathrm{wt} \%$ HPMC $\left(0.3 \mathrm{~mL}, \mathrm{pH}\right.$ 1) to $4 \mathrm{mM}$ aqueous solutions of $\mathrm{Au}^{\mathrm{III}}$ ion $(20 \mathrm{~mL}, \mathrm{pH} 1)$.

As shown in Figure S4, elongated gels were obtained. Gel elongation increased from 13 to $11 \mathrm{wt} \%$, whereas the gels formed at $9 \mathrm{wt} \%$ HPMC were shorter due to the low HPMC concentration.

(a)

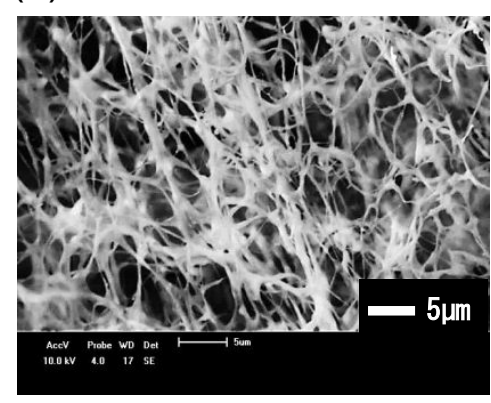

(c)

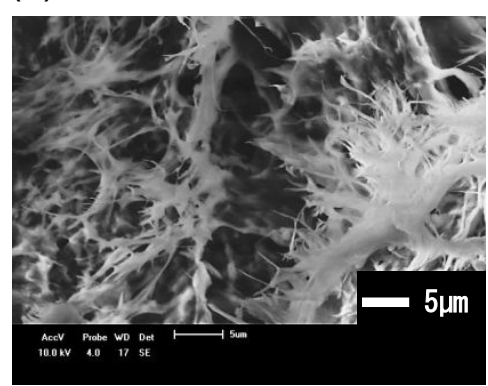

(b)

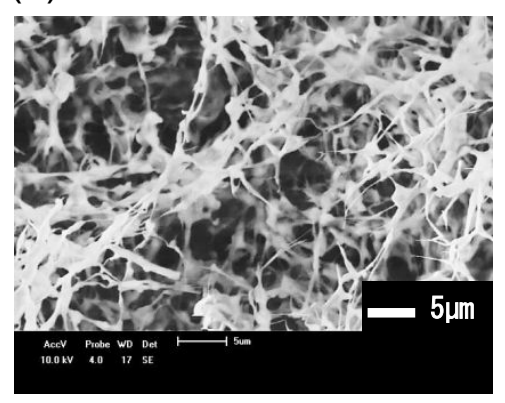


Figure S5. SEM images of gels with (a) concentration of $\mathrm{HPMC}=13 \mathrm{wt} \%,\left[\mathrm{NaAuCl}_{4}\right]_{0}=4$ $\mathrm{mM}$; (b) concentration of $\mathrm{HPMC}=12 \mathrm{wt} \%,\left[\mathrm{NaAuCl}_{4}\right]_{0}=4 \mathrm{mM}$; and (c) concentration of $\mathrm{HPMC}=11 \mathrm{wt} \%,\left[\mathrm{NaAuCl}_{4}\right]_{0}=4 \mathrm{mM}$.

The SEM observations of the obtained gels indicated that, although felt-like gels were obtained at 11 and $13 \mathrm{wt} \%$, fibrous morphology was also observed (Figure S5a and b). In contrast, the length of gels produced at $9 \mathrm{wt} \%$ was less than those produced at 11 and $13 \mathrm{wt} \%$ (Figure S5c), which is consistent with the photographic results (Figure S4c).

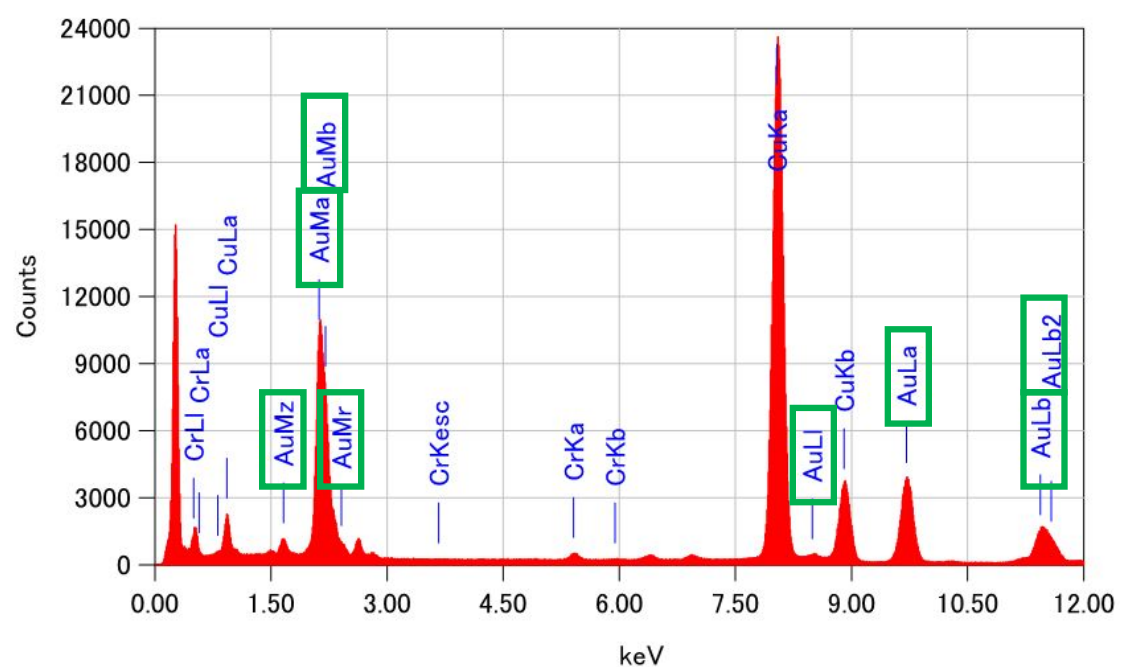

Figure S6. TEM/EDS spectrum of fibrous gels obtained by addition of a dispersed aqueous solution of $\mathrm{HPMC}(0.3 \mathrm{~mL}, 12 \mathrm{wt} \%, \mathrm{pH} 1)$ to an aqueous solution of $\mathrm{NaAuCl}_{4}(20 \mathrm{~mL}, 4 \mathrm{mM}$, $\mathrm{pH} 1)$.

The black dots observed in the TEM image (Figure 6c) were confirmed as gold (Figure S4). 

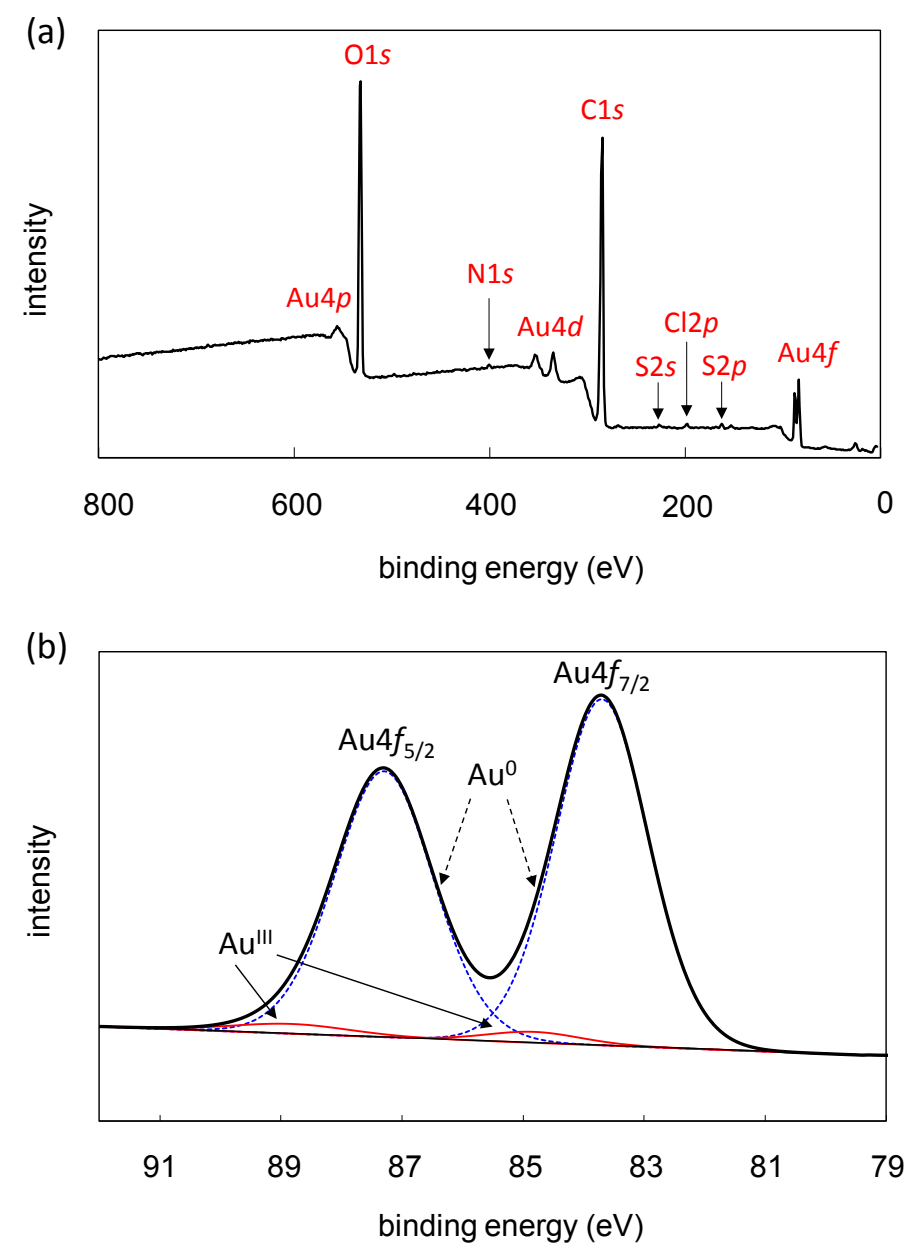

Figure S7. XPS spectra of fibrous gels obtained using $12 \mathrm{wt} \%$ HPMC dispersed in aqueous solution: (a) wide-scan spectrum and (b) narrow-scan spectrum.

The XPS wide-scan spectrum of the fibrous gel showed a small peak for $\mathrm{Cl} 2 p$ at $200 \mathrm{eV}$, indicating presence of some $\mathrm{Au}^{\mathrm{III}}$ ions (Figure S7a). The XPS narrow-scan spectrum contained Au $4 f_{5 / 2}$ and Au4 $4 f_{7 / 2}$ peaks (bold line, Figure S7b). Because the peaks for Au $4 f_{5 / 2}$ and $\mathrm{Au} 4 f_{7 / 2}$ had shoulder peaks at the high bonding energy region, they were fitted based on the Gaussian-Lorentzian (G-L) function. The peaks at 83.7 and $87.3 \mathrm{eV}$, and at 84.9 and $89.0 \mathrm{eV}$, were assigned to $\mathrm{Au}^{0}$ and $\mathrm{Au}^{\mathrm{III}}$, respectively (broken and solid lines), and the peak intensity ratio of $\mathrm{Au}^{0}$ and $\mathrm{Au} \mathrm{III}^{\mathrm{III}}$ was 28:1 for both $4 f_{5 / 2}$ and $\mathrm{Au} 4 f_{7 / 2}$ peaks. 


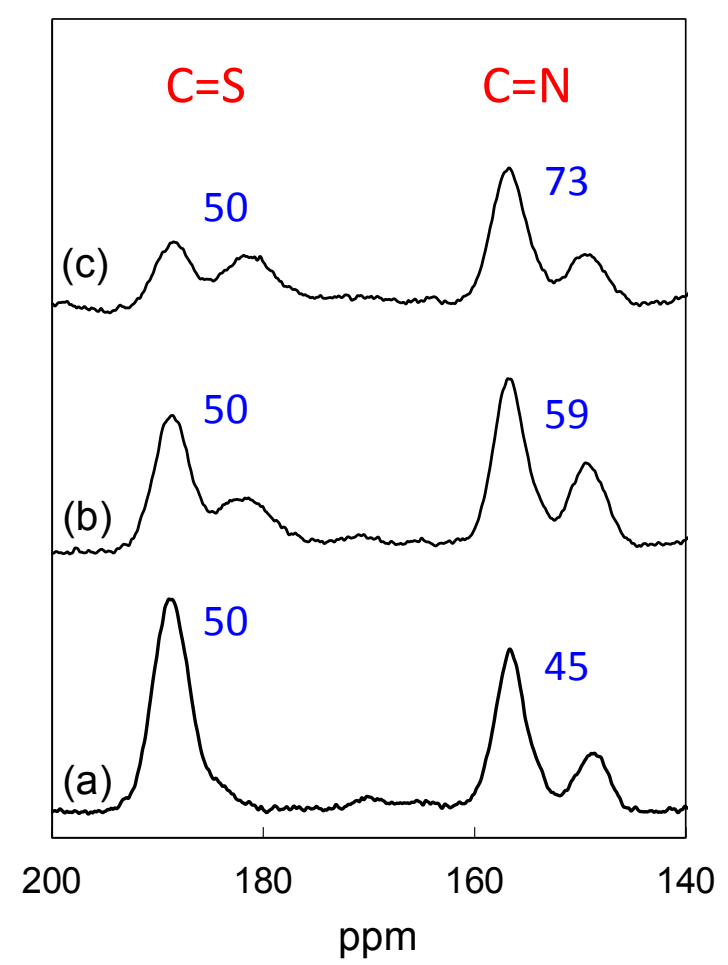

Figure S8. ${ }^{13} \mathrm{C}$ CP-MAS NMR spectra of (a) HPMC, (b) HPMC-Au (168 mg/g $\left./ \mathrm{g}_{\text {poly. }}\right)$, and (c)

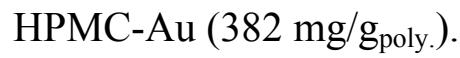

${ }^{13} \mathrm{C}$-cross-polarization/magnetic angle spinning (CP-MAS) nuclear magnetic resonance (NMR) spectroscopy was performed for HPMC-Au with different loading amounts of Au. The integral ratio of the imine groups of the thioenol structure to the thiocarbonyl groups increased with loading amount, supporting the presence of S-Au bonds (Figure S8). Additionally, the signal of the thiocarbonyl groups showed a split with increasing loading amount, indicating coordination of the thiocarbonyl groups to the gold nanoparticles. 


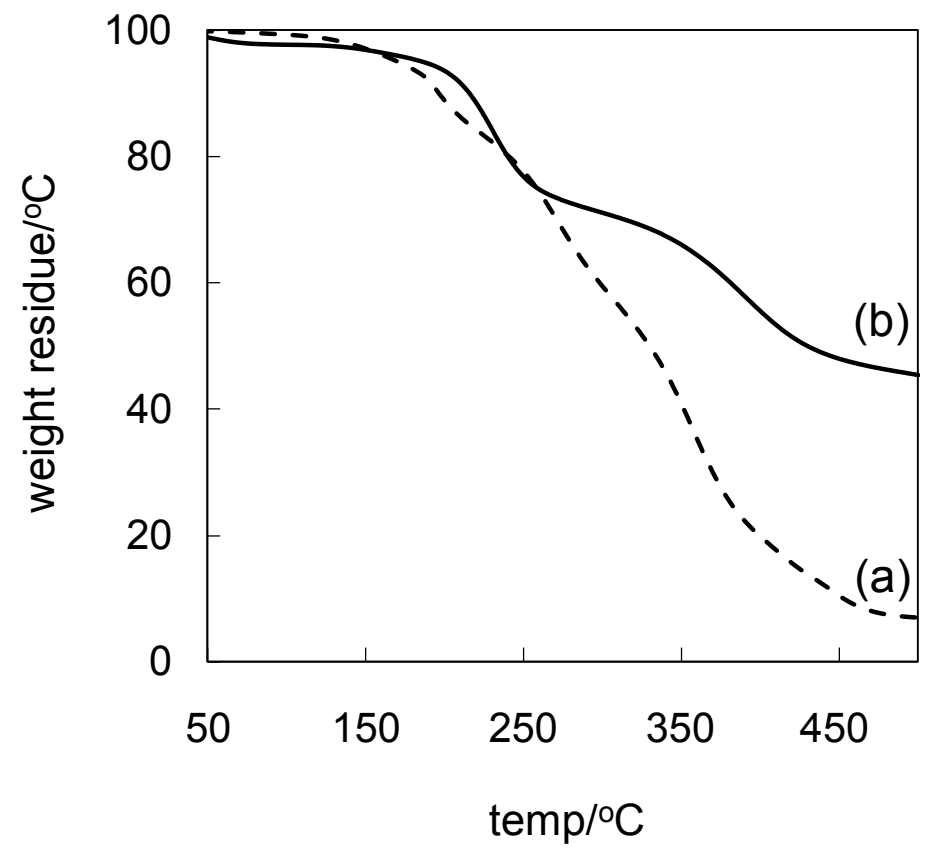

Figure S9. TG curves of (a) HPMC and (b) nano-order fibrous gels containing gold nanoparticles.

Figure S9 shows the TG curves for HPMC and the fibrous gel containing gold nanoparticles. The nano-order fibrous gel was more thermally stable than HPMC. The residue weight of the fibrous gel was $40.3 \mathrm{wt} \%$, whereas that of HPMC was $7.0 \mathrm{wt} \%$. 